\title{
Characterization of highly efficient heavy-ion mutagenesis in Arabidopsis thaliana
}

\author{
Yusuke Kazama', Tomonari Hirano ${ }^{1,2}$, Hiroyuki Saito ${ }^{1}$, Yang Liu' ${ }^{1}$ Sumie Ohbu ${ }^{1}$, Yoriko Hayashi ${ }^{1}$ and \\ Tomoko Abe ${ }^{1,2^{*}}$
}

\begin{abstract}
Background: Heavy-ion mutagenesis is recognised as a powerful technology to generate new mutants, especially in higher plants. Heavy-ion beams show high linear energy transfer (LET) and thus more effectively induce DNA double-strand breaks than other mutagenic techniques. Previously, we determined the most effective heavy-ion LET (LET max: $30.0 \mathrm{keV} \mathrm{\mu m}^{-1}$ ) for Arabidopsis mutagenesis by analysing the effect of LET on mutation induction. However, the molecular structure of mutated DNA induced by heavy ions with LET max remains unclear. Knowledge of the structure of mutated DNA will contribute to the effective exploitation of heavy-ion beam mutagenesis.

Results: Dry Arabidopsis thaliana seeds were irradiated with carbon (C) ions with $\mathrm{LET}_{\max }$ at a dose of $400 \mathrm{~Gy}$ and with LET of $22.5 \mathrm{keV} \mathrm{um}^{-1}$ at doses of $250 \mathrm{~Gy}$ or $450 \mathrm{~Gy}$. The effects on mutation frequency and alteration of DNA structure were compared. To characterise the structure of mutated DNA, we screened the well-characterised mutants elongated hypocoty/s (hy) and glabrous ( $g$ ) and identified mutated DNA among the resulting mutants by high-resolution melting curve, PCR and sequencing analyses. The mutation frequency induced by $\mathrm{C}$ ions with $\mathrm{LET}_{\max }$ was two-fold higher than that with $22.5 \mathrm{keV} \mathrm{\mu m}^{-1}$ and similar to the mutation frequency previously induced by ethyl methane sulfonate. We identified the structure of 22 mutated DNAs. Over $80 \%$ of the mutations caused by $C$ ions with both LETs were base substitutions or deletions/insertions of less than $100 \mathrm{bp}$. The other mutations involved large rearrangements.

Conclusions: The C ions with $L E T_{\max }$ showed high mutation efficiency and predominantly induced base substitutions or small deletions/insertions, most of which were null mutations. These small alterations can be determined by single-nucleotide polymorphism (SNP) detection systems. Therefore, C ions with LET max might be useful as a highly efficient reverse genetic system in conjunction with SNP detection systems, and will be beneficial for forward genetics and plant breeding.
\end{abstract}

\section{Background}

Mutation induction is a powerful tool for analysis of gene function and breeding. Among the mutagens that have been used to induce mutations, chemical mutagens such as ethyl methane sulfonate (EMS), or ionising radiation such as $\mathrm{X}$-rays or $\gamma$-rays, have been especially popular in plant science. EMS can produce point mutations, mainly G/C-to-A/T transitions, with high frequency $[1,2]$. Such point mutations are easily detected by mutation-detection systems such as the CEL1 nuclease assay or high-resolution melting curve (HRM) analysis $[3,4]$. In combination with a single-nucleotide

\footnotetext{
* Correspondence: tomoabe@riken.jp

${ }^{1}$ RIKEN Nishina Center, 2-1 Hirosawa, Wako, Saitama 351-0198, Japan

Full list of author information is available at the end of the article
}

polymorphism (SNP) detection system, EMS-mediated mutagenesis is a powerful reverse genetics approach, called Targeted Induced Local Lesions in Genomes (TILLING) [5-9]. Because of its mutation-inducing property, EMS is also very useful for producing leaky alleles in forward genetics. By contrast, X-rays and $\gamma$ rays induce DNA damage relatively randomly and cause many types of mutations including base substitutions, deletions and chromosomal alterations [10,11]. Although $\mathrm{X}$-rays and $\gamma$-rays are suitable for production of null mutations, the mutation frequency induced by X-rays and $\gamma$-rays is lower than that obtained by EMS.

Heavy-ion beams are accepted as a novel powerful mutagen because they are able to induce mutations with high frequency at a relatively low dose at which virtually
C Biomed Central

() 2011 Kazama et al; licensee BioMed Central Ltd. This is an Open Access article distributed under the terms of the Creative Commons Attribution License (http://creativecommons.org/licenses/by/2.0), which permits unrestricted use, distribution, and reproduction in any medium, provided the original work is properly cited. 
all plants survive, and they induce a broad spectrum of phenotypes without affecting other plant characteristics $[12,13]$. These characteristics of heavy-ion beams are advantageous for mutation breeding. Over 30 plant cultivars have been bred with the aid of heavy-ion beams in Japan $[14,15]$. Heavy-ion beams comprise accelerated ions produced by an ion accelerator such as a cyclotron or synchrotron. A noted physical characteristic of a heavy-ion beam is that the accelerated particles densely deposit their energy in a localized region along the particle path. This is strikingly different from $\gamma$-rays and X-rays, which sparsely deposit their energy in a large targeted volume. The degree of locally deposited energy is represented by the linear energy transfer (LET; the energy transferred per unit

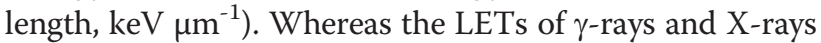

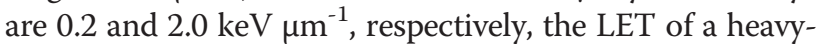
ion beam for use in biological research ranges from 22.5

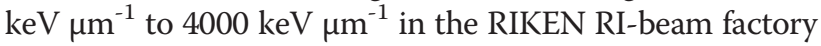
(RIBF) [16]. It is well known that high-LET radiation shows stronger biological effects than low-LET radiation. The LET of a heavy-ion beam is selectable by ion species, and depends on the characteristics of the ion with respect to electrical charge and velocity. When a high LET is required, a heavier and highly charged ion with a low velocity is selected.

Based on radiobiological considerations, it has been suggested that heavy-ion beams predominantly induce double-strand breaks (DSBs) $[17,18]$. A high yield of DSBs after heavy-ion beam irradiation was revealed by experiments on both animal and plant cells $[19,20]$. Therefore, significant DNA damage is likely to be caused by heavy-ion irradiation, although sequencing analysis of heavy-ion-induced DNA alterations is limited. Shikazono et al. reported that about half of the mutations induced by carbon (C) ions with LET of 101$124 \mathrm{keV} \mu \mathrm{m}^{-1}$ were small alterations, including base substitutions and comparatively small insertions/deletions (under $100 \mathrm{bp}$ ), whereas the other half were rearrangements such as translocations, inversions, and comparatively large insertions/deletions (over $100 \mathrm{bp}$ ) [21]. These results indicate that heavy-ion irradiation induces a broad range of mutations.

In a previous study, we found that the LET value affects the albino-mutant incidence in the $\mathrm{M}_{2}$ generation

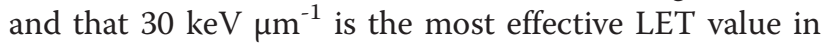
Arabidopsis thaliana mutagenesis [22]. This high-efficiency LET (termed $\mathrm{LET}_{\max }$ ) should be beneficial not only for forward genetics and breeding, but also for reverse genetics [23]. However, the mechanisms that contribute to the efficient mutagenesis of $\mathrm{LET}_{\max }$ irradiation are still unclear. Because mutagens such as EMS, $\gamma$-rays, and heavy-ion beams must be chosen appropriately depending on the experimental purpose or target genes, it is also important to know the nature of mutations induced by $\mathrm{C}$ ions with $\mathrm{LET}_{\max }$. In the present study, we investigated the relationship between mutation induction and parameters of heavy-ion irradiation, which comprised the number of irradiated ion particles and LET. We also determined mutations in knock-out mutants induced by $\mathrm{C}$-ion irradiation with $\mathrm{LET}_{\text {max }}$ in A. thaliana, as a first step to characterize the nature of $\mathrm{C}$-ion induced mutations.

\section{Results}

\section{Analysis of particle number and LET effects on mutation frequency}

To achieve increased mutation efficiency with heavy-ion irradiation, the effects of both the number of irradiated ion particles and the LET value should be studied. The number of ion particles could determine the number of DSBs per cell nucleus, while the LET value might affect the efficiency of DSB induction (see Discussion). In a previous study, we found that $\mathrm{C}$-ion irradiation with $\mathrm{LET}_{\text {max }}$ induced a three-fold higher mutation frequency

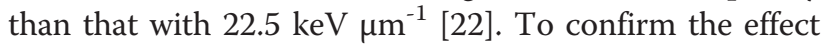
of both LET and particle number more precisely, C-ion irradiation was applied at doses that ranged from 50 to $600 \mathrm{~Gy}$; the survival percentage in the $M_{1}$ generation and albino incidence in the $\mathrm{M}_{2}$ generation were measured. The number of ion particles per cell nucleus was calculated based on the assumptions that seeds have a specific density of 1 and the size of the nucleus is 100 $\mu \mathrm{m}^{2}$ (see Methods). The dose (in Gy) is proportional to the LET (in $\mathrm{keV} \mu \mathrm{m}^{-1}$ ) and the number of irradiated particles. The effect of $\mathrm{C}$ ions with LET of $30.0 \mathrm{keV} \mu \mathrm{m}^{-}$ 1 on survival percentage was greater than that at LET of

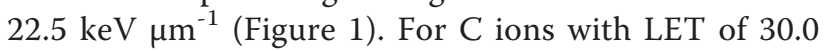

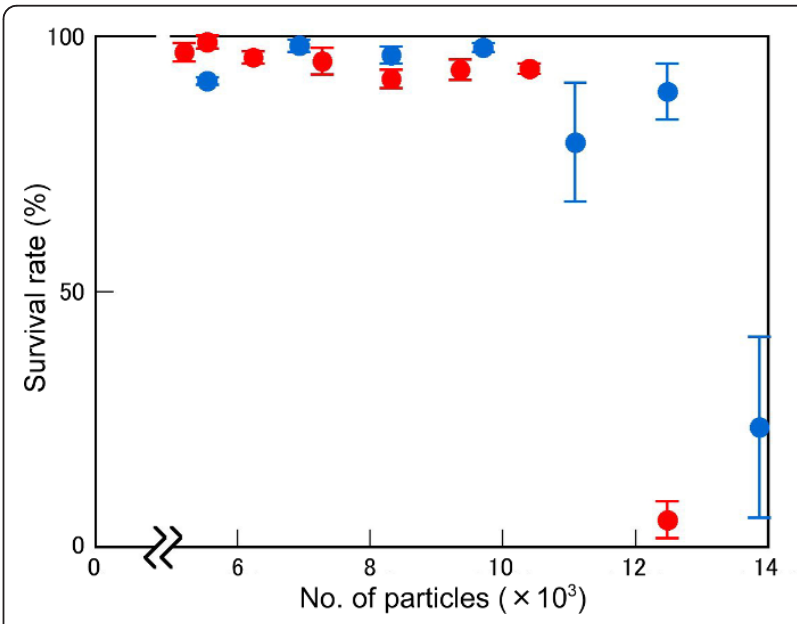

Figure 1 LET-dependent effect of $\mathbf{C}$ ions on survival. Survival (\%) was recorded 1 month after sowing C-ion irradiated seeds. Blue and red circles indicate $22.5 \mathrm{keV} \mathrm{\mu m}^{-1}$ and $30.0 \mathrm{keV} \mathrm{\mu m}^{-1} \mathrm{LET}$, respectively. 
$\mathrm{keV} \mu \mathrm{m}^{-1}$, about 12,500 particles per $100 \mu \mathrm{m}^{2}$ were

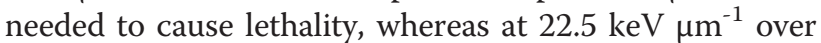
14,000 particles per $100 \mu^{2}$ were required. The LET value had a more striking effect on the mutation frequency in the $M_{2}$ generation than the $M_{1}$ generation (Figure 2). Carbon ions with LET of $30.0 \mathrm{keV} \mathrm{\mu m}^{-1}$ produced a $3.28 \%$ albino incidence at the most effective particle number $\left(8,320\right.$ per $\left.100 \mu \mathrm{m}^{2}\right)$. By contrast, $C$ ions with LET of $22.5 \mathrm{keV} \mathrm{mm}^{-1}$ produced only a $1.26 \%$ albino incidence, even at the most effective particle number $\left(12,480\right.$ per $\left.100 \mu \mathrm{m}^{2}\right)$. The difference in LET

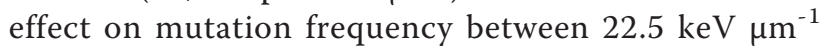
and $30.0 \mathrm{keV} \mu^{-1}$ was obvious, especially under irradiation with over 4,000 particles, which indicated that the particle number is also important to obtain a high mutation frequency. These findings indicate that $\mathrm{C}$ ions with

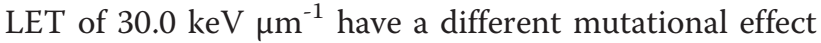

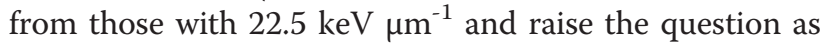
to what DNA alterations are caused by these irradiation conditions.

Confirmation of mutation efficiency of C ions with LET $\max$ The elongated hypocotyl (hy) and glabrous $(g l)$ mutants were screened in the $\mathrm{M}_{2}$ generation after C-ion irradia-

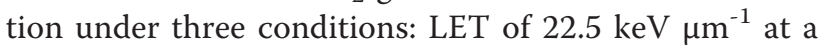
dose of 250 Gy $\left(6,933\right.$ per $\left.100 \mu \mathrm{m}^{2}\right), 22.5 \mathrm{keV} \mathrm{\mu m}^{-1}$ at a dose of $450 \mathrm{~Gy}\left(12,480\right.$ per $\left.100 \mu^{2}\right)$, and $30.0 \mathrm{keV} \mathrm{\mu \textrm {m } ^ { - }}$ ${ }^{1}$ at a dose of $400 \mathrm{~Gy}\left(8,320\right.$ per $\left.100 \mu \mathrm{m}^{2}\right)$. Mutation frequencies and the structure of mutated DNAs in these conditions were compared. The $h y$ and $g l$ mutants are well characterised and the genes responsible for the

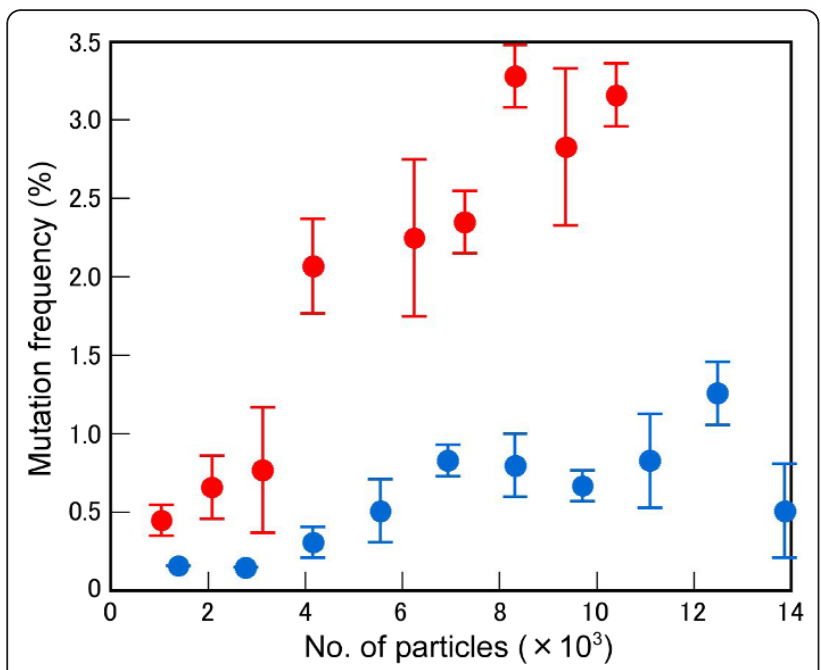

Figure 2 LET- and particle number-dependent effects of $C$ ions on mutation induction. Mutation frequencies were investigated in the $\mathrm{M}_{2}$ generation by counting the number of albino mutants $8 \mathrm{~d}$ after the onset of germination. Blue and red circles indicate $22.5 \mathrm{keV}$ $\mu \mathrm{m}^{-1}$ and $30.0 \mathrm{keV} \mathrm{mm}^{-1}$ LET, respectively. respective phenotypes have been determined [24-31]. Consequently, these mutants have been used previously for similar mutated DNA analyses [21,32,33]. Screening of $29,595 \mathrm{M}_{2}$ plants revealed that 23 mutants were induced by $\mathrm{C}$ ions with LET of $30.0 \mathrm{keV} \mathrm{\mu m}^{-1}$ at a dose

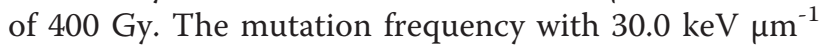
was approximately two-fold higher than that in the other irradiation conditions (Table 1). These results support the preceding data in which $C$ ions with LET of $30.0 \mathrm{keV} \mathrm{mm}^{-1}$ were more effective for mutation induc-

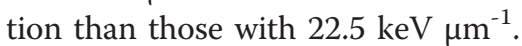

\section{Characterisation of mutated DNA structure caused by C- ion irradiation}

To investigate the structure of mutated DNA in the isolated mutants caused by $\mathrm{C}$-ion irradiation, DNA from the isolated mutants was subjected to HRM, PCR, and sequencing analyses using primers specific for the genes responsible for the $h y$ and $g l$ phenotypes (see Methods). Among the 33 hy and $g l$ mutants isolated, 18 independent mutant lines were identified. This is because mutants isolated from the same batch were thought to have originated from the same $M_{1}$ plants. To confirm that all mutants classified in the same mutant line had an identical DNA mutation, all of the mutants derived from the same batch were confirmed by PCR and sequencing analysis. Because the number of identified mutant lines was limited, the following mutants were also included in the characterisation of the DNA mutations: altered meristem program (amp) 1, pinoid (pid) 1, and yellow variegated (var) 2 (see Methods) [34-36].

The identified DNA mutations are listed in Table 2. In total, 22 mutations were identified. Mutations of 17 of the 18 independent $h y$ and $g l$ mutant lines were determined successfully. In addition, two mutations in the AMP1 gene, two mutations in the PID1 gene, and one mutation in the VAR2 gene were identified. The C-ioninduced mutations consisted of base substitutions, deletions, insertions, and translocations. Of the 22 alleles, only four showed rearrangements, including translocations and a large deletion; these were detected in highdose irradiated mutants (400 Gy and 450 Gy). Eighteen mutants had base substitutions or deletions/insertions less than $100 \mathrm{bp}$ (Tables 2 and 3). Of the four alleles with a base substitution, three were transversions and one was a transition. Among these, only one allele ( $\mathrm{C}$ 27-gl1) had a missense mutation $(D \rightarrow N)$, whereas the other alleles had nonsense mutations that resulted in production of C-terminally truncated proteins. In total, 21 alleles were null mutants. Whether the C-27-gl1 allele was a null mutation was not elucidated, although the phenotype of the C-27-gl1 mutant was similar to that of a null mutant of GL1 (data not shown). The size

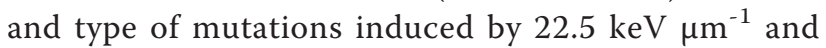


Table 1 Frequencies of hy and $g l$ mutants among plants irradiated with $C$ ions

\begin{tabular}{ccccc}
\hline $\begin{array}{c}\text { LET } \\
\left(\mathbf{k e V ~} \boldsymbol{\mu ~ m}^{-1}\right)\end{array}$ & Dose (Gy) & No. of $\mathbf{M}_{\mathbf{1}}$ plants & No. of $\mathbf{M}_{\mathbf{2}}$ plants & $\begin{array}{c}\text { No. of mutants } \\
\text { (mutation frequency (\%o) })\end{array}$ \\
\hline 22.5 & 250 & 2,024 & 11,662 & $5(0.43)$ \\
22.5 & 450 & 1,710 & 16,103 & $5(0.31)$ \\
30.0 & 400 & 3,056 & 29,595 & $23(0.78)$ \\
\hline
\end{tabular}

*Total number of isolated hy and $g /$ mutants

Mutation frequency $=$ no. of mutants $/$ no. of $\mathrm{M}_{2}$ plants $\times 10^{2}$

$30.0 \mathrm{keV} \mu \mathrm{m}^{-1}$ LET did not differ. These results indicated that C ions with LETs of 22.5 or $30.0 \mathrm{keV} \mathrm{\mu m}^{-1}$ mainly caused small alterations and that most of the induced mutants were null mutants.

Two reciprocal translocations and one complex rearrangement were detected (Figure 3). For the complex rearrangement (C30-73-gl1), only one breakpoint at the TTG1 gene was detected by TAIL-PCR. The other possible irradiation-induced breakpoints in the mutant could not be determined by any PCR analysis. However, five breakpoints were identified successfully in the mutants with rearrangements. Of the five breakpoints, four contained deletions (ranging from 9 to $28 \mathrm{bp}$ ), one had no deletion, and none had duplications (Figure 3). These five breakpoints were repaired, which resulted in six rejoined sites. Half of the rejoined sites showed short regions of sequence homology (microhomology; 2-5 bp), whereas the other half had inserted DNA fragments (3$16 \mathrm{bp}$ ), termed filler DNA [37]. Fourteen rejoining sites of simple deletions are listed in Table 3. Eight of these rejoined sites showed 1-3 bp microhomology.

\section{Discussion}

In this study, we characterised the mutation frequencies and structure of mutated DNAs in knock-out mutants caused by C-ion irradiation with LET of $22.5 \mathrm{keV} \mu \mathrm{m}^{-1}$ or $30.0 \mathrm{keV} \mu \mathrm{m}^{-1}\left(\mathrm{LET}_{\max }\right)$. The mutation frequency for C-ions with LET of $30.0 \mathrm{keV} \mu \mathrm{m}^{-1}$ was higher than that for $\mathrm{C}$ ions at $22.5 \mathrm{keV} \mu \mathrm{m}^{-1}$, as indicated by frequencies of albino mutants (Figure 2) and $h y$ and $g l$ mutants

Table 2 Mutations induced by C-ion irradiation

\begin{tabular}{|c|c|c|c|c|c|c|}
\hline 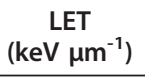 & Dose (Gy) & Allele & Mutated gene & Type of mutation* & $\begin{array}{c}\text { Size } \\
\text { (bp) }\end{array}$ & Position \\
\hline \multirow[t]{12}{*}{22.5} & 250 & C-27-gl1 & GL1 & BS & $\mathrm{G} \rightarrow \mathrm{A}$ & Chr.5: $10,363,437$ \\
\hline & & C-45-hy1 & HY4 & Del & 2 & Chr.4: 5,724,273-74 \\
\hline & & C-48-amp1 & AMP1 & BS & $A \rightarrow T$ & Chr.3: 20,255,432 \\
\hline & & C-55-hy1 & HY4 & Del & 3 & Chr.4: 5,725,528-30 \\
\hline & & C-142-hy1 & HY3 & Del & 1 & Chr.2: 8,141,902 \\
\hline & & C-162-gl1 & $\pi G 1$ & Del & 51 & Chr.5: 8,371,718-68 \\
\hline & 450 & $C(450)-100-g \mid 1$ & $\pi G 1$ & Del & 1 & Chr.5: $8,372,723$ \\
\hline & & C(450)-124-hy1 & HY3 & BS & $\mathrm{G} \rightarrow T$ & Chr.2: 8,143,452 \\
\hline & & C(450)-135-hy1 & $H Y_{1}$ & Del & 36 & Chr.2: 11,342,207-42 \\
\hline & & C(450)-139-pid1 & PID1 & RTL & & See Figure 3 \\
\hline & & C(450)-150-pid1 & PID1 & Ins & 1 & Chr.2: $14,590,504$ \\
\hline & & C(450)-154-hy1 & HY4 & Del & 32,335 & Chr.4: 5,697,598-730,031 \\
\hline \multirow[t]{11}{*}{30.0} & 400 & C30-8-gl1 & & NM & & \\
\hline & & C30-9-gl2 & GL2 & Del & 1 & Chr.1: $30,038,621$ \\
\hline & & C30-39-hy1 & HY2 & Del & 5 & Chr.3: 2,805,174-78 \\
\hline & & C30-73-gl1 & TTG1 & $C R$ & & See Figure 3 \\
\hline & & C30-74-hy1 & HY4 & Del & 2 & Chr.4: 5,725,263-64 \\
\hline & & C30-106-gl1 & GL2 & Del & 1 & Chr.1: 30,039,697 \\
\hline & & C30-108-hy1 & HY4 & RTL & & See Figure 3 \\
\hline & & C30-148-amp1 & AMP1 & Del & 1 & Chr.3: 20,257,195 \\
\hline & & C30-155-hy1 & HY2 & Del & 4 & Chr.3: 2,804,929-32 \\
\hline & & C30-252-gl1 & GL2 & BS & $C \rightarrow A$ & Chr.1: $30,040,486$ \\
\hline & & C30-273-var1 & VAR2 & Del & 23 & Chr.2: $13,175,250-72$ \\
\hline
\end{tabular}

* BS, Base substitution; CR, complex rearrangement; Del, deletion; Ins, insertion; RTL, reciprocal translocation; TL, translocation, NM, no mutation in the genes sequenced in this study.

**For base substitutions, changed bases are specified. 
Table 3 DNA insertion or deletion mutations induced by C-ion irradiation

\begin{tabular}{|c|c|c|}
\hline \multirow[t]{2}{*}{ Allele } & \multicolumn{2}{|c|}{ Sequence change } \\
\hline & Original sequence & Mutant sequence \\
\hline C-45-hy1 & TCTGGTTCTGTatCTGGTTGTGGT & $\begin{array}{l}\text { TCTGGTTCTG T } \\
\text { CTGGTTGTGGT }\end{array}$ \\
\hline C-55-hy 1 & GGCCGGACTGgatATCCGTTGGTC & $\begin{array}{l}\text { GGCCGGACTG } \\
\text { ATCCGTTGGTC }\end{array}$ \\
\hline C-142-hy1 & GATGCGATTCACTCGCTCCAGCT & $\begin{array}{l}\text { GATGCGATTCA } \\
\text { TCGCTCCAGCT }\end{array}$ \\
\hline C-162-gl1 & AGTGGTCTTCttcgc...ctccttAGAGTT & AGTGGT CTT AGAGTI \\
\hline $\begin{array}{l}\text { C(450)-100- } \\
\text { gl1 }\end{array}$ & CATGGATAATTCAGCTCCAGATT & $\begin{array}{l}\text { CATGGATAATT } \\
\text { AGCTCCAGATT }\end{array}$ \\
\hline $\begin{array}{l}\text { C(450)-135- } \\
\text { hy1 }\end{array}$ & AAAACTCAcaa...cagttcaAGAG & AAAAC TCA AGAG \\
\hline $\begin{array}{l}\text { C(450)-150- } \\
\text { pid1 }\end{array}$ & AACTCCGTTCACCGCGAC & $\begin{array}{l}\text { AACTCCGTT } T \\
\text { CACCGCGAC }\end{array}$ \\
\hline $\begin{array}{l}\text { C(450)-154- } \\
\text { hy1 }\end{array}$ & AACTAAaccgta...ggtatgGTTCA & AACTAA GTTCA \\
\hline C30-9-gl2 & TGCAGGCTATtCAAAGAGACA & $\begin{array}{l}\text { TGCAGGCTA T } \\
\text { CAAAGAGACA }\end{array}$ \\
\hline C30-39-hy1 & CATTGAACAggaaaTCCCTTAGC & $\begin{array}{l}\text { CATTGAAC A } \\
\text { TCCCTTAGC }\end{array}$ \\
\hline C30-74-hy1 & TTCTTTCTCCACACTTGC & TTCTTCT ACACTTGC \\
\hline $\begin{array}{l}\text { C30-106- } \\
\text { gl1 }\end{array}$ & AGTGTACTtCGTGAGAAG & $\begin{array}{l}\text { AGTGTAC T } \\
\text { CGTGAGAAG }\end{array}$ \\
\hline $\begin{array}{l}\text { C30-148- } \\
\text { amp1 }\end{array}$ & CTTGGGAAGaGGAGCAATT & $\begin{array}{l}\text { CTTGGGAAG } \\
\text { GGAGCAATT }\end{array}$ \\
\hline $\begin{array}{l}\text { C30-155- } \\
\text { hy1 }\end{array}$ & TGACATGGCgagcACAAAAGGT & $\begin{array}{l}\text { TGACATGG C } \\
\text { ACAAAAGGT }\end{array}$ \\
\hline $\begin{array}{l}\text { C30-273- } \\
\text { var1 }\end{array}$ & GGTTTGTtcctt...gtctggtGGTGG & GGTTT GT GGTGG \\
\hline
\end{tabular}

Deleted sequences are indicated in lower case. Overlapping sequences found in deletion sites are highlighted in bold. Inserted sequence is highlighted in bold and Italic.

(Table 1). Although the number of mutants identified is too small for accurate statistical analysis, the $h y$ and $g l$ mutation frequencies induced by $\mathrm{C}$ ions with LET of 30 $\mathrm{keV} \mu \mathrm{m}^{-1}$ are similar to that induced by EMS (0.87\%o) and 2.5 -fold higher than that induced by X-rays $(0.32 \%$ ) [38]. By contrast, the structure of mutated DNA induced

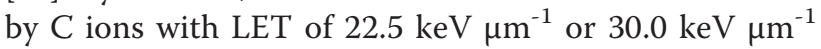
was almost identical. In both cases, over $80 \%$ of the determined mutations were small alterations and the remainder were rearrangements (Table 2). The proportion of large genetic alterations that followed repair of irradiation-induced damage might be higher than that observed in this study because a large alteration affecting an essential gene might not be transmitted to the $M_{2}$ generation [39]. Twenty-one of the 22 mutated DNAs characterised were null mutations since these mutations cause a frameshift or a nonsense mutation. The actual proportion of base substitutions induced by irradiation might be higher than that detected in this study, because some might represent silent mutations that could not be identified in the current screening.
Base substitutions and small deletions/insertions were detectable by the CEL1 nuclease assay or HRM analysis. Indeed, most of the mutations identified in this study were determined by HRM (see Methods). From our results, we suggest that $\mathrm{C}$-ion irradiation at $\mathrm{LET}_{\max }$ can be used for effective TILLING to obtain null mutants.

Mutagens must be selected according to the experimental purpose or target genes. Carbon-ion irradiation has potential advantages for several aspects of mutagenesis. First, C-ion irradiation is more practical to administer than EMS. EMS treatment of tissues or plantlets is sometimes time-consuming because of its penetration capability. On the other hand, the irradiation times required with $\mathrm{C}$-ions are short; only a few seconds irradiation is needed for imbibed seeds, tissues, and plantlets, or a few minutes for dry seeds. Indeed, by irradiation of tissue cultures or plantlets with $\mathrm{C}$-ion beams, over 20 novel cultivars in diverse plant species have been produced. Second, C-ion irradiation may be advantageous in the induction of truncation mutants rather than generation of allelic series, because our data indicated that small indel mutations occurred more frequently than base-change mutations. To generate an allelic series, EMS induction of base substitutions is useful. Finally, C-ion irradiation might have potential to induce deletions with desired sizes by selection of an appropriate LET value (see below). To clarify the beneficial characteristics of mutation induction by $\mathrm{C}$-ion irradiation, whole-genome investigation of mutations such as missense and silent mutations is needed.

The proportion of small alterations, such as base substitutions or small deletions/insertions and rearrange-

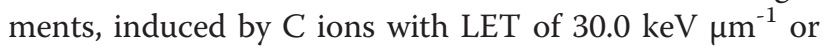

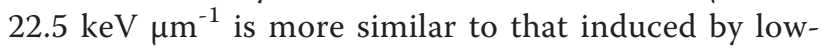
LET radiation (electrons) than that induced by $\mathrm{C}$ ions at 101-124 keV $\mu \mathrm{m}^{-1}$ LET (Table 4). Similar proportions were reported in irradiation experiments on transgenic mice, in which $\mathrm{C}$ ions with LET of $21.3 \mathrm{keV} \mu \mathrm{m}^{-1}$ preferentially induced small alterations (68\%), as did $\gamma$-rays (71\%) [40]. Suzuki et al. reported that the proportions of large and small deletions differed between $C$ ions with

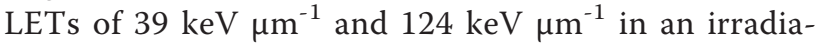
tion experiment on human cells [41]. These data indicate that $C$ ions with moderate LET (around $30 \mathrm{keV}$ $\mu \mathrm{m}^{-1}$ ) might have different effects on DNA alterations from $\mathrm{C}$ ions with LET of 101-124 $\mathrm{keV} \mu \mathrm{m}^{-1}$. However, the structure of breakpoints was similar between the current study $\left(22.5 \mathrm{keV}_{\mu \mathrm{m}}{ }^{-1}\right.$ or $\left.30.0 \mathrm{keV} \mu \mathrm{m}^{-1}\right)$ and a

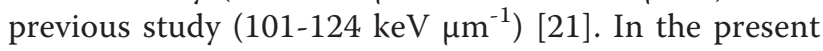
study, five of the six breakpoints of rearrangements had deletions, whereas no breakpoint contained a duplication (Figure 3). A previous study revealed that the breakpoints induced by C ions with LET of 101-124 $\mathrm{keV} \mu \mathrm{m}^{-1}$ preferentially have deletions (11 out of 17 ), 


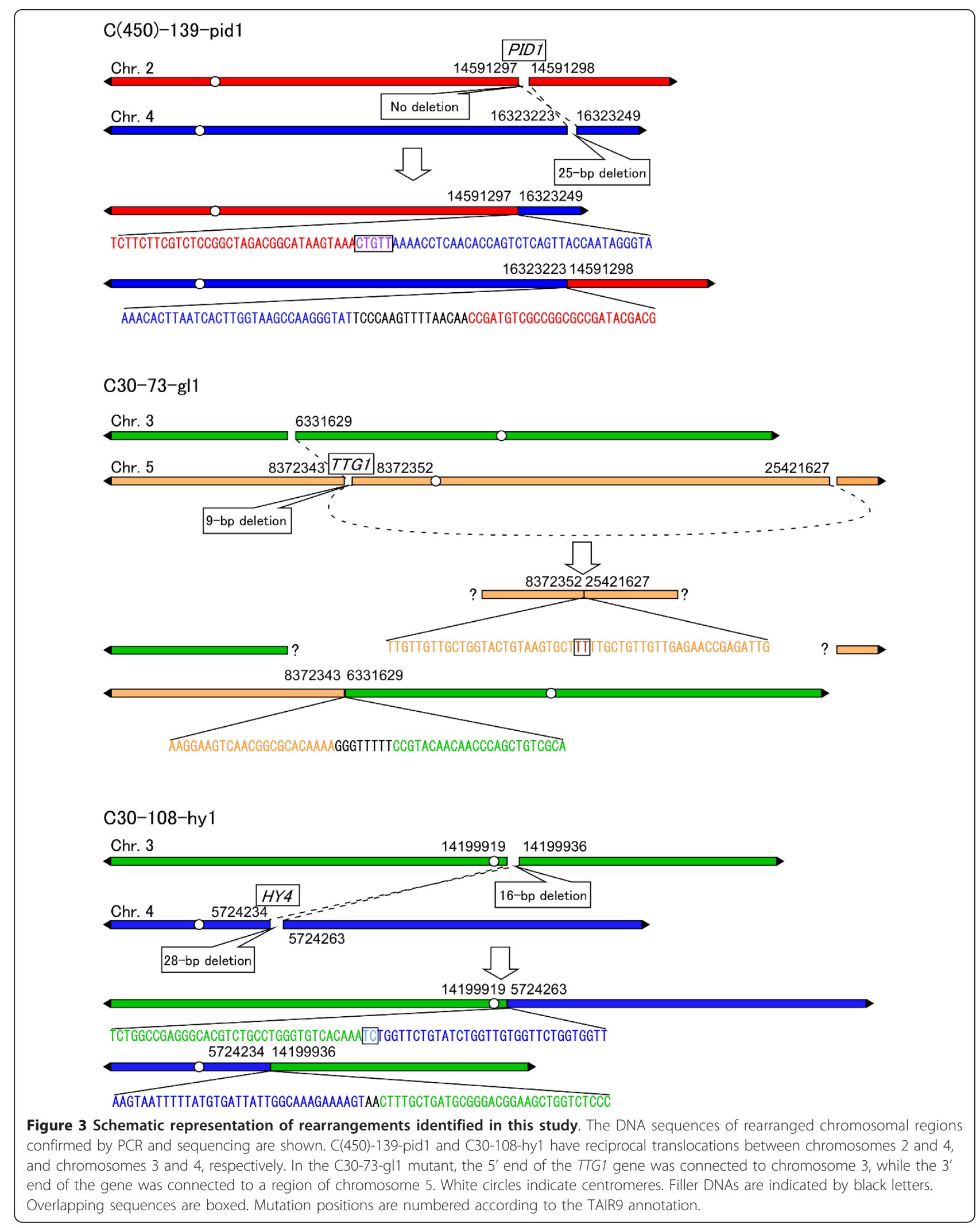


Table 4 Classification of mutations induced by electron and C-ion irradiation

\begin{tabular}{|c|c|c|c|}
\hline Radiation & Small alterations* $(\%)$ & Rearrangements* (\%) & Reference \\
\hline$\overline{\text { Electron }\left(0.2{\left.\mathrm{keV} \mu \mathrm{m}^{-1}\right)}\right)}$ & $9(75.0)$ & $3(25.0)$ & {$[21]$} \\
\hline 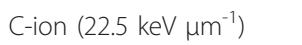 & $10(83.3)$ & $2(16.7)$ & This study \\
\hline C-ion $\left(30.0 \mathrm{keV} \mu \mathrm{m}^{-1}\right)$ & $8(80.0)$ & $2(20.0)$ & This study \\
\hline C-ion $\left(101-124 \mathrm{keV}_{\mu} \mathrm{m}^{-1}\right)$ & $14(48.3)$ & $15(51.7)$ & {$[21]$} \\
\hline
\end{tabular}

* Small alterations comprise 1-100 bp deletions/insertions and base substitutions. Rearrangements comprise deletions/insertions exceeding 100 bp, translocations, reciprocal translocations and inversions.

whereas the breakpoints induced by electrons tend to have duplications (6 out of 8) [21]. These results imply that the process of DSB production and repair after irradiation with $C$ ions with LETs of $22.5 \mathrm{keV} \mu \mathrm{m}^{-1}$ or 30.0 $\mathrm{keV} \mu \mathrm{m}^{-1}$ might be similar to those with 101-124 keV $\mu \mathrm{m}^{-1}$. Therefore, $30.0 \mathrm{keV} \mu \mathrm{m}^{-1}$ appears to represent a moderate LET between low-LET radiation and 101-124 $\mathrm{keV} \mu \mathrm{m}^{-1}$.

Previously, we had no clear answer to the question of why $\mathrm{C}$ ions with $30 \mathrm{keV} \mu \mathrm{m}^{-1}$ LET can induce a higher mutation frequency than other LET values. The current study showed no difference in the structure of mutated

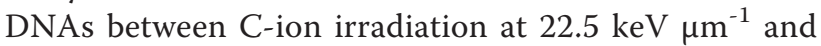
$30 \mathrm{keV} \mu \mathrm{m}^{-1}$. Thus, the DSB repair process in both conditions might be the same, although the possibility of existence of a LET-dependent DNA repair pathway cannot be excluded. One possible explanation for the difference in mutation frequencies between these irradiation conditions is the difference in the efficiency of DSB production. Although the number of irradiated particles with LET of $22.5 \mathrm{keV} \mathrm{\mu m}^{-1}$ was larger than that with

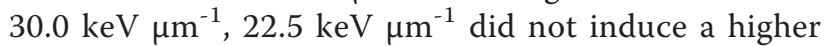
mutation frequency than $30.0 \mathrm{keV} \mu \mathrm{m}^{-1}$ (Figure 2). Therefore, it is likely that $30.0 \mathrm{keV} \mathrm{m}^{-1} \mathrm{C}$ ions induced

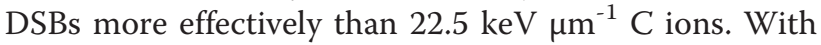
regard to $C$ ions with LET values exceeding $30.0 \mathrm{keV}$ $\mu \mathrm{m}^{-1}$, the mutation frequency was not higher than that of $\operatorname{LET}_{\max }\left(30 \mathrm{keV} \mathrm{\mu m}^{-1}\right)$ [22]. Under these irradiation conditions, the particle number might not be sufficient to produce the same mutation effect as that with LET of $30 \mathrm{keV} \mu \mathrm{m}^{-1}$. For example, with irradiation of 4,000 particles per $100 \mu \mathrm{m}^{2}$ at $61.5 \mathrm{keV} \mu \mathrm{m}^{-1}$, the absorbed dose reached about $400 \mathrm{~Gy}$, at which point the $\mathrm{M}_{1}$ plants could not survive [22]. Collectively, our results indicate that both an appropriate LET value and an adequate particle number might be needed to obtain the highest mutation efficiency with heavy-ion beam irradiation.

Alternatively, the difference in DSB qualities might be a possible explanation for the LET-dependent difference in mutation induction efficiency between $22.5 \mathrm{keV} \mathrm{\mu m}^{-1}$ and $30.0 \mathrm{keV} \mu \mathrm{m}^{-1}$. Monte Carlo calculations indicate that high-LET radiation induces a higher fraction of complex DSBs than low-LET radiation $[42,43]$ and complex DSBs are difficult to repair $[44,45]$. The data from the Monte
Carlo calculations are in good accordance with experimental measurements of the higher yield of short DNA fragments after high-LET irradiation in both animals and plants $[20,46]$. Therefore, it is likely that the quality of

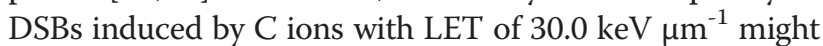
be slightly more complex than that induced by $\mathrm{C}$ ions with LET of $22.5 \mathrm{keV} \mathrm{\mu m}^{-1}$, and that the complex DSBs might be difficult to repair, although more-detailed theoretical and experimental data with LETs around $30.0 \mathrm{keV}$ $\mu \mathrm{m}^{-1}$ are required to clarify this hypothesis.

The current data indicate that the structures of mutated DNA caused by C-ion irradiation with LETs of $22.5 \mathrm{keV}$ $\mu \mathrm{m}^{-1}$ or $30.0 \mathrm{keV} \mu \mathrm{m}^{-1}$ differed from those induced by C-

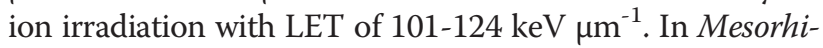

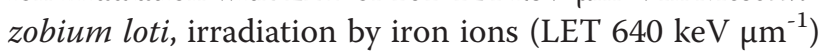
induced larger deletions compared with deletions induced by $\mathrm{C}$ ions (LET $23 \mathrm{keV} \mathrm{\mu m}^{-1}$ ) [47]. These results raise the possibility that the structure of mutated DNA might be controlled by selection of an appropriate LET value. To achieve this, further experimental data under irradiation conditions with different LETs is needed as well as theoretical analysis of the quality of DSBs.

\section{Conclusions}

$\mathrm{C}$ ions at $\mathrm{LET}_{\max }$ showed higher mutation efficiency than those with LET of $22.5 \mathrm{keV} \mu \mathrm{m}^{-1}$, with an efficiency that appears similar to that with EMS. To achieve such efficiency with heavy-ion beam irradiation, both LET and particle number must be optimised. In Arabidopsis, $30.0 \mathrm{keV} \mathrm{\mu m}^{-1}$ at 400 Gy $\left(8,320\right.$ per $\left.100 \mu \mathrm{m}^{2}\right)$ was the most effective dose. C ions at $\mathrm{LET}_{\max }$ and 22.5 $\mathrm{keV} \mu \mathrm{m}^{-1}$ predominantly induced null mutations. Over $80 \%$ of the null mutations were base substitutions or small deletions/insertions, which can be detected by SNP detection systems such as the CEL1 nuclease assay or HRM analysis. It is concluded that $C$ ions with LET of $30.0 \mathrm{keV} \mu \mathrm{m}^{-1}$ might be suitable as a powerful TILLING technology in conjunction with a SNP detection system to produce null mutants.

\section{Methods}

\section{Irradiation treatment}

Dry seeds of $A$. thaliana ecotype Columbia (Col-0) were packed in a plastic bag to obtain a monolayer of seeds. 
The seeds were irradiated with ${ }^{12} \mathrm{C}^{6+}$ ions $\left(22.5 \mathrm{keV} \mu \mathrm{m}^{-1}\right.$

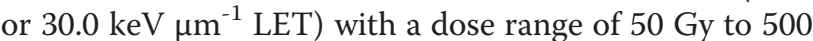
Gy using the $\mathrm{E} 5$ beam line in the RIKEN RI-beam factory. The ions were accelerated up to $1.62 \mathrm{GeV}$, at which the LET value of the ${ }^{12} \mathrm{C}^{6+}$ ions was $22.5 \mathrm{keV} \mu \mathrm{m}^{-1}$. The LET value of the ${ }^{12} \mathrm{C}^{6+}$ ions was adjusted to $30.0 \mathrm{keV} \mu \mathrm{m}^{-1}$ by reducing the velocity of the ions. To reduce the ion velocity, the ions were passed through a combination of absorbers [48]. All LET values were calculated behind the seeds. The irradiated $M_{1}$ seeds were surface-sterilised by dipping in $1 \%$ sodium hypochlorite for $10 \mathrm{~min}$, washed five times with sterilised water, and incubated on $0.7 \%$ agar-containing Murashige and Skoog (MS) medium supplemented with MS vitamins and $3 \%$ sucrose at $4{ }^{\circ} \mathrm{C}$ in the dark for $4 \mathrm{~d}$ to induce vernalisation. Subsequently, the seeds were incubated at $22^{\circ} \mathrm{C}$ under long-day conditions (16 h light, $8 \mathrm{~h}$ dark). Seedlings that developed true leaves were transplanted into plastic trays $\left(13 \times 9 \mathrm{~cm}^{2}\right)$ that contained soil. Eleven seedlings were planted in each tray and grown at $22^{\circ} \mathrm{C}$ under long-day conditions in a greenhouse. The $\mathrm{M}_{2}$ seeds were collected from all plants in each tray and were treated as one batch.

\section{Analysis of particle effect on plant survival and DNA mutation}

Measurement of percentage survival of irradiated $M_{1}$ seeds and albino incidence in the $M_{2}$ generation was performed as described previously [22]. At least three independent experiments at different doses of irradiation were carried out for each LET value. To estimate the number of particles per cell nucleus, the number of particles at each dose was calculated for a water area of $100 \mu \mathrm{m}^{2}$ with a specific gravity of 1 , as described previously [49].

\section{Mutant screening and identification of mutated genes}

From the $\mathrm{M}_{2}$ generation, elongated hypocotyl (hy) and glabrous $(g l)$ mutants were screened by germination of the $\mathrm{M}_{2}$ seeds on MS agar medium. $\mathrm{M}_{2}$ plants that showed the $h y$ and $g l$ phenotypes were isolated. Genomic DNA was purified from the isolated mutant and wild-type plants four weeks after germination using the DNeasy Plant Mini Kit (QIAGEN, Hilden, Germany). The purified DNAs were subjected to HRM analysis using primers specific for the putative mutated genes (HY1, HY2, HY3, and HY4 for the hy mutants; GL1, GL2, and TTG1 for the $g l$ mutants; see Additional file 1). HRM analysis was performed on a LightCycler 480s (Roche Diagnostics, Penzberg, Germany) in a reaction mixture that contained $10 \mathrm{ng}$ wild-type DNA, $10 \mathrm{ng}$ mutant DNA, $0.5 \mathrm{mM}$ of each primer, and $3 \mathrm{mM}$ $\mathrm{MgCl}_{2}$ in the LightCycler 480 High Resolution Melting Master containing ResoLight dye (Roche Diagnostics) adjusted to a total volume of $10 \mu \mathrm{l}$ with PCR-grade water. The reaction conditions comprised an activation step at $95^{\circ} \mathrm{C}$ for $10 \mathrm{~min}$ followed by 50 cycles of $95^{\circ} \mathrm{C}$ for $10 \mathrm{~s}$, a touchdown of $65^{\circ} \mathrm{C}$ to $55^{\circ} \mathrm{C}$ for $10 \mathrm{~s}\left(0.5^{\circ} \mathrm{C}\right.$ cycle $\left.^{-1}\right)$, and $72^{\circ} \mathrm{C}$ for $10 \mathrm{~s}$. Before the HRM step, the products were heated to $95^{\circ} \mathrm{C}$ for $1 \mathrm{~min}$ and frozen to $40^{\circ} \mathrm{C}$ for $1 \mathrm{~min}$. HRM analysis was carried out over the range from $65^{\circ} \mathrm{C}$ to $95^{\circ} \mathrm{C}$, rising at $4.4^{\circ} \mathrm{C} \mathrm{s}^{-1}$ with 25 acquisitions per degree. All reactions were performed in replicate (duplicate or triplicate) in 96-well plates. When a positive signal was identified, the amplified fragment was sequenced using the Big Dye Terminator v. 3.1 Cycle Sequencing Kit (Applied Biosystems) and a 3730xl DNA Analyser (Applied Biosystems) with the same primers as those used for HRM analysis. When the whole or part of the coding region could not be amplified, flanking sequence analysis using TAIL-PCR was performed [50]. Primers used for flanking sequence analysis are listed in Additional file 2. Because of the limited number of $h y$ and $g l$ mutant lines identified, mutations induced in three additional well-characterised morphological mutants, namely altered meristem program (amp) 1 [34], pinoid (pid) 1 [35], and yellow variegated (var) 2 [36], were isolated and their mutated genes were determined by PCR or HRM analysis and sequenced using specific primers (see Additional files 1 and 2). The $\mathrm{M}_{3}$ seeds of the mutants were harvested and the phenotype of the $M_{3}$ plants was analysed to confirm whether the phenotype of the mutants was inherited.

\section{Additional material}

Additional file 1: Primers used for HRM.

Additional file 2: Primers used for other PCR analyses.

\section{Acknowledgements}

We thank the RIKEN Research Resources Center of the Brain Science Institute for performing DNA sequencing. This experiment was performed at RIBF operated by the RIKEN Nishina Center and CNS, University of Tokyo. We also acknowledge the Internship Program for Chinese Graduate Students affected by Sichun Earthquake from RIKEN for YL. This work was partially supported by grants from the research project Utilizing Advanced Technologies in Agriculture, Forestry and Fisheries from the Ministry of Agriculture, Forestry and Fisheries of Japan, Social Infrastructure Technology Development Program from RIKEN and the Funding Program for Next Generation WorldLeading Researchers, initiated by the Council for Science and Technology Policy from the Japan Society for the Promotion of Science for TA. This work was also supported by Grants-in-Aid for Scientific Research (no. 20780009 and no. 23770070 to YK) from the Ministry of Education, Culture, Sports, Science and Technology of Japan, and the Special Postdoctoral Research Program of RIKEN (to YK).

\section{Author details}

${ }^{1}$ RIKEN Nishina Center, 2-1 Hirosawa, Wako, Saitama 351-0198, Japan. ${ }^{2}$ RIKEN Innovation Center, 2-1 Hirosawa, Wako, Saitama 351-0198, Japan.

\section{Authors' contributions}

TA conceived the study, designed the research, coordinated the project and obtained the beam times. YK and TA participated in the design of the 
molecular genetic analyses. YK, TH, HS, SO, YH, and TA performed C-ion irradiation. $Y K, T H, H S, Y L$, and $S O$ conducted mutant screening. $Y L$ and $S O$ participated in growing plants. $\mathrm{YK}, \mathrm{TH}$, and $\mathrm{YL}$ carried out the molecular genetic analyses. YK and TA were primarily responsible for drafting and revising the manuscript with contributions from the co-authors. All authors read and approved the final manuscript.

Received: 9 June 2011 Accepted: 15 November 2011 Published: 15 November 2011

\section{References}

1. Richardson FC, Richardson KK: Sequence-dependent formation of alkyl DNA adducts: a review of methods, results, and biological correlates. Mutat Res 1990, 233:127-138.

2. Greene EA, Codomo CA, Taylor NE, Henikoff JG, Till BJ, Reynolds SH, Enns LC, Burtner C, Johnson JE, Odden AR, Comai L, Henikoff S: Spectrum of chemically induced mutations from a large-scale reverse-genetic screen in Arabidopsis. Genetics 2003, 164:731-740.

3. McCallum CM, Comai L, Greene EA, Henikoff S: Targeted screening for induced mutations. Nature Biotech 2000, 18:455-457.

4. Wittwer $C T$, Reed GH, Gundry CN, Vandersteen JG, Pryor RJ: High-resolution genotyping by amplicon melting analysis using LCGreen. Clin Chem 2003, 49:853-860.

5. Till BJ, Reynolds SH, Weil C, Springer N, Burtner C, Young K, Bowers E, Codomo CA, Enns LC, Odden AR, Greene EA, Comai L, Henikoff S: Discovery of induced point mutations in maize genes by TILLING. BMC Plant Biol 2004, 4:12.

6. Till BJ, Cooper J, Tai TH, Colowit P, Greene EA, Henikoff S, Comai L: Discovery of chemically induced mutations in rice by TILLING. BMC Plant Biol 2007, 7:19.

7. Cooper JL, Till BJ, Laport RG, Darlow MC, Kleffner JM, Jamai A, El-Mellouki T, Liu S, Ritchie R, Nielsen N, Bilyeu KD, Meksem K, Comai L, Henikoff S: TILLING to detect induced mutations in soybean. BMC Plant Biol 2008, $8: 9$

8. Cooper JL, Till BJ, Laport RG, Darlow MC, Kleffner JM, Jamai A, El-Mellouki T, Liu S, Ritchie R, Nielsen N, Bilyeu KD, Meksem K, Comai L, Henikoff S: A modified TILLING approach to detect induced mutations in tetraploid and hexaploid wheat. BMC Plant Biol 2009, 9:115.

9. Shirley BW, Hanley S, Goodman HM: Effects of ionizing radiation on a plant genome: analysis of two Arabidopsis transparent testa mutations. Plant Cell 1992, 4:333-347.

10. Cecchini E, Mulligan BJ, Covey SN, Miner JJ: Characterization of gamma irradiation-induced deletion mutations at a selectable locus in Arabidopsis. Mutation Res 1998, 401:199-206.

11. Morita R, Kusaba M, lida S, Yamaguchi H, Nishio T, Nishimura M: Molecular characterization of mutations induced by gamma irradiation in rice. Genes Genet Syst 2009, 84:361-370.

12. Abe T, Bae CH, Ozaki T, Wang K, Yoshida S: Stress tolerant mutants induced by heavy -ion beams. Gamma Field Symp 2000, 39:45-54.

13. Tanaka A, Shikazono N, Hase Y: Studies on biological effects of ion beams on lethality, molecular nature of mutation, mutation rate, and spectrum of mutation phenotype for mutation breeding in higher plants. $J$ Radiat Res 2010, 51:223-233.

14. Miyazaki K, Suzuki K, Iwaki K, Kusumi T, Abe T, Yoshida S, Fukui H: Flower pigment mutations induced by heavy ion beam irradiation in an inter specific hybrid of Torenia. Plant Biotech 2008, 23:163-167.

15. Kanaya T, Saito H, Hayashi $Y$, Fukunishi N, Ryuto H, Miyazaki K, Kusumi T, Abe T, Suzuki K: Heavy-ion beam-induced sterile mutants of verbena (Verbena $\times$ hybrida) with an improved flowering habit. Plant Biotech 2008, 25:91-96.

16. Ryuto H, Fukunishi N, Hayashi Y, Ichida H, Abe T, Kase M, Yano Y: Heavyion beam irradiation facility for biological samples in RIKEN. Plant Biotech 2008, 25:119-122.

17. Ward JF: The complexity of DNA damage: relevance to biological consequences. Int I Rad Biol 1994, 66:427-432.

18. Goodhead DT: Molecular and cell models of biological effects of heavy ion radiation. Radiat Environ Biophys 1995, 34:67-72.

19. Hoglund E, Blomquist E, Carlsson J, Stenerlow B: DNA damage induced by radiation of different linear energy transfer: initial fragmentation. Int $J$ Radiat Biol 2000, 76:539-547.
20. Yokota Y, Yamada S, Hase Y, Shikazono N, Narumi I, Tanaka A, Inoue M: Initial yields of DNA double-strand breaks and DNA Fragmentation patterns depend on linear energy transfer in tobacco BY-2 protoplasts irradiated with helium, carbon and neon ions. Radiat Res 2007, 167:94-101.

21. Shikazono N, Suzuki C, Kitamura S, Watanabe H, Tano S, Tanaka A: Analysis of mutations induced by carbon ions in Arabidopsis thaliana. J Exp Bot 2005, 56:587-596.

22. Kazama $Y$, Saito $H$, Yamamoto $Y Y$, Hayashi $Y$, Ichida H, Ryuto H, Fukunishi $N$, Abe T: LET-dependent effects of heavy-ion beam irradiation in Arabidopsis thaliana. Plant Biotech 2008, 25:113-117.

23. Shitsukawa N, Ikari C, Shimada S, Kitagawa S, Sakamoto K, Saito H, Ryuto H, Fukunishi N, Abe T, Takumi S, Nasuda S, Murai K: The einkorn wheat (Triticum monococcum) mutant, maintained vegetative phase, is caused by a deletion in the VRN1 gene. Genes Genet Syst 2007, 82:167-170.

24. Koornneef M, Rolff E, Spruit CJP: Genetic control of light-inhibited hypocotyl elongation in Arabidopsis thaliana (L) Heynh. Z Pflanzenphysiol 1980, 100:147-160

25. Reed JW, Nagpal P, Poole DS, Furuya M, Chory J: Mutations in the gene for the red far-red light receptor phytochrome-B alter cell elongation and physiological responses throughout Arabidopsis development. Plant Cell 1993, 5:147-157.

26. Ahmad M, Cashmore AR: HY4 gene of A. thaliana encodes a protein with characteristics of a blue-light photoreceptor. Nature 1994, 366:162-166.

27. Muramoto T, Kohchi T, Yokota A, Hwang $\mathbb{H}$, Goodman HM: The Arabidopsis photomorphogenic mutant hy 1 is deficient in phytochrome chromophore biosynthesis as a result of a mutation in a plastid heme oxygenase. Plant Cell 1999, 11:335-347.

28. Kohchi T, Mukougawa K, Frankenberg N, Masuda M, Yokota A, Lagarias JC: The Arabidopsis HY2 gene encodes phytochromobilin synthase, a ferredoxin-dependent biliverdin reductase. Plant Cell 2001, 13:425-436

29. Walker AR, Davison PA, Bolognesi-Winfield AC, James CM, Srinivasan N, Blundell TL, Esch JJ, Marks MD, Gray JC: The TRANSPARENT TESTA GLABRA1 locus, which regulates trichome differentiation and anthocyanin biosynthesis in Arabidopsis, encodes a WD40 repeat protein. Plant Cell 1999, 11:1337-1350.

30. Oppenheimer DG, Herman PL, Sivakumaran S, Esch J, Marks MD: A myb gene required for leaf trichome differentiation in Arabidopsis is expressed in stipules. Cell 1991, 67:483-493.

31. Rerie WG, Feldmann KA, Marks MD: The GLABRA2 gene encodes a homeo domain protein required for normal trichome development in Arabidopsis. Genes Dev 1994, 8:1388-1399.

32. Bruggemann E, Handwerger K, Essex C, Storz G: Analysis of fast neutrongenerated mutants at the Arabidopsis thaliana HY4 locus. Plant J 1996, 10:755-760.

33. Shikazono N, Tanaka A, Watanabe H, Tano S: Rearrangements of the DNA in carbon ion-induced mutants of Arabidopsis thaliana. Genetics 2001, 157:379-387.

34. Helliwell CA, Chin-Atkins AN, Wilson IW, Chapple R, Dennis ES, Chaudhury A: The Arabidopsis AMP1 gene encodes a putative glutamate carboxypeptidase. Plant Cell 2001, 13:2115-2125.

35. Christensen SK, Dagenais N, Chory J, Weigel D: Regulation of auxin response by the protein kinase PINOID. Cell 2000, 100:469-478.

36. Takechi K, Sodmergen Murata M, Motoyoshi F, Sakamoto W: The YELLOW VARIEGATED (VAR2) locus encodes a homologue of FtsH, an ATPdependent protease in Arabidopsis. Plant Cell Physiol 2000, 41:1334-1346.

37. Gorbunova V, Levy AA: How plants make ends meet: DNA double-strand break repair. Trends Plant Sci 1999, 4:263-269.

38. Koornneef M, Dellaert LW, van der Veen JH: EMS- and radiation-induced mutation frequencies at individual loci in Arabidopsis thaliana (L.) Heynh. Mutat Res 1982, 93:109-123.

39. Naito K, Kusaba M, Shikazono N, Takano T, Tanaka A, Tanisaka T, Nishimura M: Transmissible and nontransmissible mutations induced by irradiating Arabidopsis thaliana pollen with gamma-rays and carbon ions. Genetics 2005, 169:881-889.

40. Masumura K, Kuniya K, Kurobe T, Fukuoka M, Yatagai F, Nohmi T: Heavyion-induced mutations in the gpt delta transgenic mouse: comparison of mutation spectra induced by heavy-ion, X-ray, and gamma-ray radiation. Environ Mol Mutagen 2002, 40:207-215.

41. Suzuki M, Watanabe M, Kanai T, Kase Y, Yatagai F, Kato T, Matsubara S: LET dependence of cell death, mutation induction and chromatin damage 
in human cells irradiated with accelerated carbon ions. Adv Space Res 1996, 18:127-136.

42. Ottolenghi A, Merzagora M, Tallone L, Durante M, Paretzke HG, Wilson WE: The quality of DNA double-strand breaks: a Monte Carlo simulation of the end-structure of strand breaks produced by protons and alpha particles. Radiat Environ Biophys 1995, 34:239-244.

43. Alloni D, Campa A, Belli M, Esposito G, Facoetti A, Friedland W, Liotta M, Mariotti L, Paretzke HG, Ottolenghi A: A Monte Carlo study of the radiation quality dependence of DNA fragmentation spectra. Radiat Res 2010, 173:263-271.

44. Blocher D: DNA double-strand break repair determines the RBE of alphaparticles. Int J Radiat Biol 1988, 54:761-771.

45. Pastwa E, Neumann RD, Mezhevaya K, Winters TA: Repair of radiationinduced DNA double-strand breaks is dependent upon radiation quality and the structural complexity of double-strand breaks. Radiat Res 2003, 159:251-261.

46. Lobrich M, Cooper PK, Rydberg B: Non-random distribution of DNA double-strand breaks induced by particle irradiation. Int I Radiat Biol 1996, 70:493-503.

47. Ichida H, Matsuyama T, Ryuto H, Hayashi Y, Fukunishi N, Abe T, Koba T: Molecular characterization of microbial mutations induced by ion beam irradiation. Mutat Res 2008, 639:101-107.

48. Ryuto H, Abe T, Fukunishi N, Kase M, Yano Y: Heavy-ion beam irradiation system for biological samples in RIKEN. J Biomed Nanotech 2006, 2:88-93.

49. Scholz M: Dose response of biological systems to low- and high-LET radiation. In Microdosimetric response of physical and biological systems to low- and high-LET radiations 2006. Edited by: Horowitz Y. Oxford, UK: Elsevier; 2006:1-73.

50. Liu YG, Mitsukawa N, Oosumi T, Whittier RF: Efficient isolation and mapping of Arabidopsis thaliana T-DNA insert junctions by thermal asymmetric interlaced PCR. Plant J 1995, 8:457-463.

doi:10.1186/1471-2229-11-161

Cite this article as: Kazama et al: Characterization of highly efficient heavy-ion mutagenesis in Arabidopsis thaliana. BMC Plant Biology 2011 11:161.

\section{Submit your next manuscript to BioMed Central and take full advantage of:}

- Convenient online submission

- Thorough peer review

- No space constraints or color figure charges

- Immediate publication on acceptance

- Inclusion in PubMed, CAS, Scopus and Google Scholar

- Research which is freely available for redistribution

Submit your manuscript at www.biomedcentral.com/submit 